\title{
An evaluation of a Macmillan GP clinical facilitator project: the post-holders' perspective
}

Christine Ingleton School of Nursing and Midwifery, University of Sheffield, Sheffield, UK, Philippa Hughes University of Sheffield, Trent Palliative Care Centre, Sheffield, UK, Bill Noble Northern General Hospital, Sheffield, UK, Hermina M Gray Pengorof Surgery, Swansea, UK and David Clark Academic Palliative Medicine Unit, Royal Hallamshire Hospital, Sheffield, UK

\begin{abstract}
There is evidence to suggest that GPs experience significant difficulties associated with lack of support from, and communication with, hospital and other specialists in palliative care. The establishment of cancer and palliative care facilitator schemes by Macmillan Cancer Relief reflects these current concerns very clearly. This paper presents some of the findings from the first phase of an evaluation of one such GP facilitator scheme in the Welsh county of Powys. It examines the perceptions and expectations of GP facilitator post-holders during the first year of the facilitator scheme, based upon data gathered from qualitive interviews conducted on three separate occasions. The picture that emerges from the first year of this facilitator project is broadly a positive one. Facilitators have tailored their roles to fit in with and augment the practices with which they deal. Attitudes vary, but their goals of facilitation and education appear similar. The main challenges facing post-holders is that of being aware of the possible existence of professional rivalries whilst developing their role in ways which do not encroach upon the territories of long-established colleagues.
\end{abstract}

Key words: general practitioners; GP clinical facilitators; models of facilitation; endof-life care; formative evaluation; rural palliative care

\section{Introduction and background}

Most palliative care is provided within the community by the primary care team yet it has been estimated that the average general practitioner (GP) will encounter only two patients per annum in need of specialist palliative care (NCHSPCS, 1995). Although many other patients will have generic palliative care needs, this relatively infrequent exposure to this particular client group can make it difficult for GPs both to develop and then to maintain the necessary expertise. At the same time, there is evidence that GPs experience significant difficulties associated with lack of support from, and communication with, hospital and other

\footnotetext{
Address for correspondence: Dr Christine Ingleton, School of Nursing and Midwifery, University of Sheffield, Winter Street, Sheffield, S3 7ND, UK. Email: m.c.ingleton@sheffield.ac.uk
}

specialists in palliative care (Addington-Hall and McCarthy, 1995; Easthaugh, 1996; Seale and Cartwright, 1994). Meanwhile, the need for more education and training, especially in relation to symptom control, communication and caring for patients with nonmalignant conditions remains a continuing theme in the primary care literature (Boyd, 1995; Robbins, 1998; Seamark and Thorne, 1993). Yet, educational programmes have often met with limited GP support (Grande, 1997; Shipman et al., 2001b), possibly due to lack of awareness of gaps in their own training. That said, recent studies (Barclay et al., 1999; Boyd, 1995; Field, 1998; Robbins, 1998) suggest that primary healthcare team members regard palliative care as a high priority and recognise their frontline position in being the most likely source of support and help for people with palliative care needs. The introduction of GP facilitators to co-ordinate palliative care education in primary healthcare teams - a scheme 
started initially as a pilot in five areas in a collaborative project between the Royal College of General Practitioners (RCGP) and the Macmillan Cancer Relief reflects current concern very clearly. This paper presents some of the findings from the first phase of an evaluation of one such GP facilitator scheme in the Welsh county of Powys and takes the perspective of the GP facilitator post-holders. We describe the origins of the model of facilitator intervention, as well as that adopted in Powys, and then explore the perceptions and expectations of post-holders during the first year of the facilitator scheme, based upon data gathered from qualitative interviews conducted on three separate occasions.

\section{The development and evaluation of GP facilitator schemes in the UK}

The impetus for the establishment of cancer and palliative care facilitator schemes in the early 1990s grew from a realization by Macmillan and the RCGP that community-based palliative care places considerable demands upon general practitioners and other members of the primary healthcare team in meeting the needs of this particular client group (Cox et al., 1995). Little was known of the involvement of general practitioners in the management of the dying patient, yet it was recognized that with a significant number of people dying at home, general practitioners and their teams must regularly be in contact with such patients (RCGP and CRMF, 1995). At the time, it was unclear whether general practitioners were able to provide an effective and high quality palliative care service in the community (Blyth, 1990; Cartwright, 1990). Consequently, initial work, under the auspices of the RCGP, considered a model of facilitation for improving care by the use of facilitators to provide advice and support in a context where general practitioners share the expertise developed within their own field to address these issues.

Subsequently, a rolling programme of GP palliative and cancer care facilitator appointments has been developed with the following aim:

To enhance the continuity and quality of cancer and palliative care in the community by providing experienced general practitioners to work as educational facilitators with primary health care teams to help mobilise, enhance and develop existing professional skills.

There are currently around 60 Macmillan facilitators in post (Thomas and Millar, 2001) in which the charity works in partnership with a local 'host' organization which adds its own distinctive aims to local projects. However, with a few notable exceptions (Cox et al., 1995; Munday et al., 1999; Shipman etal., 2001a), evaluations of such schemes have been sparse in both number and critical orientation.

\section{Developing a model of facilitation for Powys}

Three problems were thought to exist when considering the development of a suitable model of cancer and palliative care facilitator intervention in Powys. First, local GPs held varying perspectives on how the role of facilitator might be operationalized in practice. Second, GPs were either unable or unwilling to give 'protected' time to the facilitation role. Third, many GPs were uncertain about how additional money from Macmillan could usefully be spent, given that GPs were already providing palliative care to patients in their own homes and in local community hospitals. For these reasons, the standard model of GP facilitation, whereby GPs implement educational interventions in other practices was dismissed as unworkable and undesirable in the Powys context.

The first appointments to the facilitator role in Powys were made in February 1999 and by June 1999, 12 facilitators had taken up post. Employed for one session per week, these facilitators are taking part in a 3-year intervention project which has the following aims:

- To provide extended clinical care (see Box 1) in palliative care to both cancer and noncancer patients by agreement of all doctors in practices in the designated areas;

- To provide an educational intervention to raise the standards of generalist palliative care in practices in the designated areas;

- To work with the health authority to ensure a co-ordinated and integrated framework for the commissioning and provision of specialist cancer and palliative care for the county. 
We undertook an evaluation of this scheme, commissioned by Macmillan Cancer Relief, in partnership with Powys Health Care NHS Trust, proceeding in two phases. Phase 1 of the evaluation (1999-2000) would be essentially exploratory in nature and focus on the experiences, perceptions and activities of the GP facilitators. Phase 2 (2000-2002) would then focus on measuring the effectiveness and impact of the facilitator intervention. In this paper, we present findings from phase 1 of the evaluation.

\section{Local context}

Powys is the largest of the Welsh counties, as well as the most sparsely populated and its general practices often cover wide geographical areas. It is made up of several independent communities with significant distances between them. It has neither a district general hospital within its boundaries, nor designated specialist palliative care beds, though there are some designated GP palliative care beds. Considerable use is therefore made of the $10 \mathrm{com}$ munity hospitals and the majority of patients requiring inpatient palliative care remain under the care of their GPs. All of the Powys general practices make use of community hospital beds. Cancer deaths in Powys average 361 per annum, compared with average annual deaths from all causes in Powys (1995-1997) of 1404 (Department of Public Health, Dyfed Powys Health Authority, 1999).

\section{Method and sample}

Previous experience (Billings, 2000; Ingleton et al., 1998; Pawson and Tilley, 1997) in conducting evaluation studies of new service developments has revealed the difficulties which can arise: low up-take of the service in the early stages; initial setbacks and 'teething' problems; anxieties among those being 'evaluated'; and changes to initial project aims. Accordingly, the evaluation team (comprising expertise in the social sciences, nursing and medicine) adopted a participatory and consultative mode of working, designed to both minimize disruption and pressure on those involved and to place a strong emphasis upon appropriate feedback and dissemination of findings.
A range of data collection methods was used, taking into account the perspectives of a full range of stakeholders, and drawing upon a variety of data sources. The methods employed for phase 1 of the study are set out in Box 2. This paper draws upon the data from interviews with facilitators. Data related to other aspects of the study are reported elsewhere (Noble et al., 2001).

\section{Box 1 Categorisation of palliative care services and settings}

\section{Characteristics and care setting}

Level 1 The use of palliative care principles or an 'approach' which may be discerned within general practitioner services or within longterm institutions, such as nursing homes.

Level 2 The presence of trained and accredited specialist practitioners who use their skills to provide extended clinical care in a range of nonspecialist settings.

Level 3 A high concentration of trained staff with access to a range of specialized expertise and in which services are provided either at home or in a specialist setting.

\section{Source: Clark and Seymour (1999)}

The sample comprised all GP facilitators appointed to the project across Powys $(n=12)$. There are 18 general practices and 10 community hospitals in Powys. Facilitators were initially appointed to eight practices, linked to eight of the 10 community hospitals. Six of the facilitators were female and six were male, and two facilitators held a university diploma in palliative care.

Interviews were semistructured and were carried out at the start of the evaluation, approximately 6 months later, and at the conclusion of the first year of the project. An aide-memoire was used to guide 
interviews, focussing broadly on four main sections (see Box 3).

\section{Box 2 Data collection methods employed in phase 1 of the evaluation}

Diary records completed by clinical facilitators

Semistructured interviews with (at three points during phase 1) GP clinical facilitators

Semistructured interviews with specialist providers in Powys and beyond

Documentary analysis (including demographic and epidemiological records)

Postal questionnaire survey of all general practitioners and district nurses, and a purposive sample of community hospital Staff

\section{Box 3 Topics areas covered in interviews with facilitators}

(1) Interest in palliative care, expectations and perceptions of the facilitator role and how it could be developed

(2) Relationships with nonspecialist and specialist providers of palliative care

(3) Main barriers to delivering palliative care in Powys

(4) SWOT analysis (strengths, weaknesses, opportunities and threats) of the facilitator project to-face. A few of the second interviews (two) and all of the third interviews were conducted by telephone to reduce the amount of travelling required on the part of the researchers, and to allow greater flexibility for both parties in choosing time and place. Several studies (Bariball et al., 1996; Sibbald et al., 1994) have demonstrated that telephone interviewing has particular benefits when the sample is geographically spread, or when working within a continually changing environment, as was the case in this study. Two interviewers ( $\mathrm{CI}$ and $\mathrm{PH}$ ) carried out the interviews, which typically lasted between 30 and $40 \mathrm{~min}$. All interviews were tape-recorded with consent using high quality, specialized recording equipment. The use of this type of equipment was a necessary prerequisite to conducting successful interviews via the telephone.

\section{Analysis of data}

All interview data were fully transcribed and two researchers (CI and $\mathrm{PH}$ ) read all transcriptions. Data were open coded (Strauss and Corbin, 1990), that is, data were broken down into discrete parts, closely re-examined and compared for similarities and differences. This process achieved a series of categories and themes and these were written and discussed with members of the research team and confirmed by examination of transcript excerpts. Each piece of data that related to a theme was 'lifted' from the interview transcripts and regular meetings were held to confirm coding decisions, compare analyses and agree on conclusions. Findings from this analysis were presented to participants, not only as a 'check on validity', but as a means of collecting additional data, stimulating further analysis, involving participants in the evaluation, and stimulating action on findings and recommendations.

\section{Findings}

Four major themes emerged from the analysis:

- Starting out

- Role boundaries 
- Gaining and maintaining credibility

- Quantity versus quality.

\section{Starting out}

There was considerable enthusiasm among all facilitators at the start of the project, with 'exciting' a frequently used descriptor. The project's strengths were perceived as two-fold. First, it was an opportunity both to focus attention on palliative care issues within general practice locally and to develop a model of service provision which could have relevance outside Powys. Second, it was perceived as a possible route for facilitators' own professional clinical development, which might, in turn, offer the potential for improvement in care and better communication between GPs. The following excerpt encapsulates the views of most of the post-holders:

Strengths, I mean you know it's enormously exciting, but there are all sorts of potential strengths of it, its going to raise awareness, its going to I think raise standards. I think it's going to improve communication among GPs which is quite important here and at the end of the day be very good for the GPs and the patients really ... (8/1)

Whilst there was widespread acknowledgement of the potential value of the role, this was tempered by some degree of apprehension about the magnitude of the task, matched by a concern over the amount of time which could be allocated to it:

It's at the stage of having opened that door and looking through and being aware of the huge subject of palliative care locally ... and of course finding the time ... (1/1)

This group of GPs were self-selected for the posts, all (except one) by means of noncompetitive interviews. This was seen as being of significance and, in some instances, crucial to the success of the project:

I think that the strength of the project is that it's using people who are already in post and who in many ways are self selected because they want to live in a rural area which possibly has greater responsibility, challenges because of the distances from the DGH. So I think that, the GPs are, are of a good calibre to begin with. So I think that's one of its main strengths. (3/1)
One post holder put it more emphatically:

It often stands or falls on the quality of the facilitator you've got (4/1)

There was a range of reasons for interest in the clinical facilitator posts. Post-holders felt they and their colleagues generally, regarded palliative care as an integral and satisfying part of their practice. As one facilitator explained:

It's been a kind of interest in the practice, and we've all done - we all become involved in palliative care, I think the vast majority of patients with cancer choose to die at home in this area, and it's - it is something that can usually be achieved, because families are very supportive on the whole and they have the - the community hospital as well to provide backup ... (1/1)

Although work with dying patients was seen as important and rewarding it was not usually seen as being particularly different from the rest of a general practitioner's work. Similarly, palliative care was often spoken of as a concern and responsibility of all GPs in the practices, though there were also instances where existing structures within a practice might lend themselves to one partner developing a particular 'clinical niche' in palliative care - this could occur for example in group practices where special interests were already evident. A facilitator in one such practice explained:

I thought 'right, for the practice this would be good, not just for us personally, but for the whole area and we, the partners within the practice have different specialties, two of them are general surgeons, two are anaesthetists, so it was felt there was an area lacking, and we can help the others like they're helping us with our other problems ... (2/1)

\section{Role boundaries}

Facilitators were asked about their relationships with members of the primary healthcare team. They pointed out that the different circumstances of general practice in Powys required an alternative model from that adopted for facilitators in England. GPs in Powys had often chosen to work there because of the independence required of them, the opportunity for an extended role, particularly in the 
community hospitals, and the possibilities for continued care of patients through many stages of their lives:

Speaking for the partners they're afraid that we are gonna take over their terminally ill patients; and after all some have been GPs for 30 odd years and don't want that, they want to look after them to the end; and we keep saying well we won't be taking them over, we'll be there in an advisory role only if you want us ... (6/2)

Such GPs, it was suggested, were likely to be selfreliant, to have considerable experience in looking after patients with palliative care needs and their families, and to have a commitment to close involvement with their care, often continuing to visit personally towards the end of a patient's life, rather than 'handing over' to colleagues. Moreover, such care was seen as embedded in family and community relationships because of a rural context in which GPs were likely to have built up a relationship prior to the onset of their terminal illness.

Contact with partners in connection with the facilitator project was seen by some post-holders as a delicate area, with a concern not to be heavyhanded in the approach to colleagues already experienced in delivering palliative care:

The partners are all very experienced and have been doing palliative care for longer than myself ... I don't think we've got a very major problem ... they're not afraid of using morphine, for example, ... but the other thing is, maybe we should have more of an interest in their patients. I think at the beginning $\mathrm{X}$ and I thought that ... let's not interfere with what other people are doing with their patients, because it's a bit intimidating to them, however I think now in order to find out exactly what they are doing, maybe we should be looking at the notes, or perhaps discussing more with the nurses ... (9/3)

Moreover, facilitators were keenly aware that not holding a recognized qualification in palliative care could leave them in a vulnerable position:

I think one of the weaknesses at the start was that the GPs are all at different levels, those who've got a diploma already have a much clearer understanding of the way things should be taken forward. Those who haven't clearly, have to get themselves up to speed. (4/3)

This situation was a significant issue in the Powys scheme where facilitators could feel vulnerable and somewhat exposed when carrying out their educative role with other members of their peer group:

... I think the problem is trying to educate our partners when really speaking we haven't had any more education in palliative care (than they have). (10/2)

All facilitators were clear that they did not wish to adopt an 'expert' or specialist role but did recognize the paradoxical pressures from other stakeholders who had expectations that post-holders would act as a resource for advice and information, relieving some of the pressures on specialist providers.

Sometimes attempts to involve partners did not yield much success and nine months into the project, this remained an unresolved issue for some post-holders. Facilitators were therefore thinking carefully about what approach they might adopt next:

I've got nowhere at all with the medical staff ... within the practice ... I haven't really explored very much why the other partners aren't interested, although I've a good idea why they're not interested; they just feel basically that they've got other things going ... I think they rather feel that me taking on this is ... me becoming a palliative care specialist ... $(5 / 3)$

Such remarks illustrate some of the difficulties that newly established facilitators face in gaining credibility and legitimacy in the eyes of established systems of care where territorial boundaries may be jealously guarded. Although the establishment of a new role was not intended to supersede existing provision, it does by definition suggest some inadequacies within it. For this reason, careful consideration was given to how best to approach GP colleagues, with some facilitators using one of the project tasks (setting up a cancer register) as a means of chipping away at traditional role boundaries:

this [the cancer register] is a useful way of interacting with my colleagues without feel- 
ing that I'm taking any of their clinical responsibilities. (2/2)

\section{Gaining and maintaining credibility}

Maintaining credibility among their GP partners was especially important and central to the 'success' or otherwise of the facilitators' work on the project: without this they could not hope to influence the culture, direction or implementation of evidence-based palliative care. The completion of a university diploma in palliative care was viewed as an important means to gaining such credibility.

All facilitators expressed high levels of commitment to continuing professional education. Yet, balancing the competing demands of their everyday work-load with those of undertaking study for a diploma in palliative care sometimes resulted in a sense of overload. Information relating to all aspects of palliative care was readily available (often because of involvement in the facilitator project), but perhaps in quantities greater than could easily be absorbed, requiring some selection to make this information manageable. A particular concern for a number of facilitators was the mechanism for enhancing and improving their own palliative care skills, and the standards against which the care could then be measured:

we've got to be sure that our knowledge is sufficient. One way of course is by doing this diploma course. The other thing I would like to do ... is to go to Holme Towers (inpatient hospice out of county) ... and maybe have two or three study days ... if we had more contact ... we'd have a better idea of what was expected by today's standards. (11/1)

This close clinical contact of the so-called 'sitting with Nellie' type of clinical teaching was an integral part of learning about contemporary practice for many of the post-holders. Similarly, informal and 'unplanned' discussions with specialist colleagues based around patient referrals were the preferred method of acquiring up-to-date knowledge. Most facilitators valued this as an opportunity for two-way learning. It may, however, be less popular with specialists chiefly because it is so timeconsuming.

\section{Quantity versus quality}

A theme emerging from all the interviews concerned the complex balance between the quality and quantity dimensions of the facilitator role, in other words, the perceived difficulties associated with fulfilling the role in a context where time is limited and priorities were often competing. On the quantity side, several facilitators identified workload variations:

It's bursts of activity ... nothing seems to be happening for a while, and every now and then it's palliative care ... let's get on with it. $(8 / 2)$

I got to a point when I wonder if I am doing anything, but things over the last two or three weeks have hotted up ... (4/2)

The reasons for these feelings of "not doing enough' varied, although there was consensus that facilitators were rarely able to set aside a regular designated session each week for their Macmillan work, so their activities were necessarily intermittent. Allied to this, work of facilitators involves opportunistic networking and developing the consultative and educational aspects of the role with other professionals. This is somewhat atypical in the context of general practice, where work is usually much more planned and tangible. Nevertheless, we found that the level of activity recorded in the diaries completed by facilitators appeared to indicate a commitment over and above the normal one session per week, although precise quantification of these data was not possible due to incomplete records.

Moreover, it should be borne in mind that this study took place against a backdrop of unparalleled change as primary care entered yet another uncertain phase of far reaching reorganization. This meant further demands upon time, as GPs were expected to take on an increasingly wide range of tasks. The start of the facilitator project coincided with the impact of New Labour reforms to health services in Wales, in the context of a devolved regional assembly. These included the abolition of fund-holding and the introduction of local health care groups (LHCGs) in Wales. Each of these groups operates at four levels of complexity, from an advisory role in health authority commissioning to commissioning care for their population on the basis of a public health function for the locality (Barclay et al., 1999). Unlike the groups in England, those in Wales have no budgetary control, at least initially. General practitioners are 
required to run the boards of primary care groups, in conjunction with nurses and other primary care staff (Oldham and Rutter, 1999). A key feature is the concept of clinical governance, which, for the first time, requires explicit clinical standards including clinical audit, use of evidence-based practice and processes to pick up and address underperformance (Lipman, 2000). Further, the formation of these groups has added responsibility for commissioning services to the GPs' role as service provider and gatekeeper of secondary care. One facilitator recognised the magnitude and ramifications of these changes and summarized the issue clearly:

Threats to the project possibly time constraints, and with the re-organisation of general practice and the formation of a local health group, and the amount of commitment that will involve, that's a threat on the way general practice will be working and the whole pressures we'll be put under, personally I'd much rather be involved with the palliative care project than all the rearrangement, but there's no way of avoiding some commitment to the local health care group ... the changes are coming and they will have a massive impact on the whole way general practice is seen and functions ... $(12 / 1)$

Whilst there were reservations about work-load and time constraints, there were no such worries concerning the quality of palliative care offered, although it was acknowledged that there were always areas which could be improved:

there is perhaps a feeling I could do better, there's always been, and you read about it and you hear about it, the feeling because of that sense of failure that you should be curing people ... (2/3)

Community hospitals were seen as having a central role in the delivery of good quality palliative care. Some facilitators described the community hospitals as more comparable with care at home than with care in acute hospitals, although it should be noted that community hospitals within the region vary considerably in terms of bed numbers and the range of treatments and services available. The hospitals were seen as an extension of primary care insofar as they enable GPs and primary healthcare teams to support people within their own communities and provide intermediate care:

It's [community hospital] an extension of their home and it is part of the community so kids pop in and out on their way to school and it's, I mean it's enviable because it, it works. (4/2)

Rural communities were spoken of as tending to be self-reliant, so people are more likely to put up with symptoms for longer without seeking advice. Community hospitals were therefore very significant in the provision of in-patient care, and the role of the GP was considered different from most other areas in the UK because of their responsibilities for community hospital beds. The decision, then, to reduce the number of beds in the community hospital of Powys from 415 to 289 (Powys Health Care NHS Trust, 1999) was viewed by many GPs as a retrograde step and one which could potentially have a major impact on care provision in the future:

For our patients it would be devastating ... for example, needing respite would have to try and get them in a hospice, there's a waiting list, they'd just have to go to the district general hospital. (1/3)

\section{Discussion}

For most facilitators, the overarching concern was to carve a 'niche' that would complement and augment rather than supplant any existing provision. It was acknowledged that this could be a slow and incremental process and one that would require careful negotiation, trust building and a 'light touch' before new post-holders were able to fully integrate their work within an established network of providers.

This study also underlines a fundamental, yet frequently overlooked premise that any role is invariably a reflection of the individual assuming the direction, scope and responsibilities of that role. Dombeck (1997) describes this phenomenon in terms of 'professional personhood'. In other words, the individual is defined by a capacity for cognition and communication, possession of knowledge and skills, emotional and experiential capabilities, as well as by membership of a professional group. In these terms, the establishment 
of a group of GPs with an interest in and commitment to improving palliative care provision is a major strength of the project. This commitment is demonstrated in their self-selection to the project and in their motivation to undertake continuing professional development. The personal strengths of the individual post-holders in terms of their flexibility and willingness and ability to work in a multidisciplinary way were also crucial to the success of the project.

It should be noted that this study took place against a backcloth of huge change in the organisation of general practice as a whole. In the light of continued reorganizations, attempts are being made to define the nature of 'general practice' and its 'core values' have themselves become contentious issues (Kumar, 2000). On the one hand, there is resistance to relinquishing the ideal of GPs as autonomous providers of integrated, and generalist medical care; while on the other there a desire to develop the more recent role as providers of increasingly specialized care. The GPs in this study appeared to view the changing landscape as an opportunity for developing and extending intermediate skills within general practice and forging links with other providers of primary and secondary care (c.f. Kendrick and Hilton, 1997).

There are two enduring strengths of general practice. The first is the continuous longitudinal relationship with patients and family members which produces 'personal knowledge' that may enable the general practitioner to match appropriate services to the particular needs of the client group. The second is the particular expertise of the GP whose clinical skills, it could be argued, are adapted to the undifferentiated nature of clinical problems presented in primary care in the context of a 'low technology' setting (Fugeli and Heath, 1996). For many of the facilitators we interviewed, the community hospital was viewed as one of the vehicles for affording opportunity to provide this locally accessible, longitudinal and integrated care. Community hospitals have an important role in the provision of palliative care and have been shown to deliver very good standards of care (Seamark et al., 2001). Yet at a time when community hospitals are being expanded in the UK, Powys, where the present study was conducted, is reducing the number of available beds, albeit on a more limited basis than first believed. Nevertheless there remains a concern that the planned bed closures will place an increasing burden on an already overstretched service. Crisis admissions during busy winter months and the paucity of nursing home beds in Powys may further add to the concerns.

\section{Conclusion}

In conclusion, the picture that emerges from the first year of this facilitator project is broadly a positive one. The very existence of palliative care facilitator in the region brings the issue of palliative care into the spotlight. Facilitators have tailored their roles to fit in with and augment the practices with which they deal. Their attitudes vary, but their goals of facilitation and education appear similar. Post-holders regard palliative care as an integral and satisfying part of their practice and the project was viewed as an opportunity to raise the profile of palliative care both locally and nationally. The focus from the outset has been on the importance of shaping the 'intervention' in a variety of ways, according to local need, and in a rapidly changing context where the magnitude of that change represents a major challenge to all involved in primary care. This flexible approach appears to be enabling facilitators to adapt readily to changing situations, whilst also allowing greater scope for other colleagues to exercise their own autonomous expertise and judgement. However, the main challenge facing post-holders is that of being aware of the possible existence of professional rivalries, whilst having to develop their role in ways that do not encroach upon the territories of long-established colleagues. This has to be reconciled with the possible paradoxical tensions from other stakeholders in the initiative who have expectations that facilitators will act as a resource and thus relieve some of the pressures on specialist providers. These issues will need constant attention if post-holders in the Powys project are to become effective 'facilitators' of palliative care in their local communities.

\section{Acknowledgements}

The study was commissioned and funded by Macmillan Cancer Relief. Approval for the evaluation was granted from the local Research Ethics Committee. 


\section{References}

Addington-Hall, J. and McCarthy, M. 1995: Regional study of care for the dying: methods and sample characteristics. Palliative Medicine 9, 27-35.

Barclay, S., Todd, C., McCabe, J. and Hunt, T. 1999: Primary care group commissioning of services: the differing priorities of GPs and DNs for palliative care services. British Journal of General Practice 49, 181-6.

Bariball, K., Christian, K., While, A. 1996: The telephone survey method: a discussion paper. Journal of Advanced Nursing 23, 1177-85.

Billings, J. 2000: Community development: a critical review of approaches to evaluation. Journal of Advanced Nursing 31 (2), 472-80.

Blyth, A.C. 1990: Audit of terminal care in general practice. British Medical Journal 300, 983-6.

Boyd, K.J. 1995: The role of specialist home care teams: views of general practitioners in South London. Palliative Medicine 9, $138-44$.

Cartwright, A. 1990: The role of the general practitioner in caring for people in the last year of their lives. London: King's Fund.

Clark, D. and Seymour, J. 1999: Reflections on palliative care. Buckingham: Open University Press.

Cox, I., Waine, C., Bolas, R. et al. 1995: General practice palliative care facilitator project 1992-1994: Report of an evaluation. London: Royal College of General Practitioners.

Department of Public Health, Dyfed Powys Health Authority. 1999: Powys local health group: Health and social factors 1999: Dyfed Powys Health Authority.

Dombeck, M. 1997: Professional personhood: training, territoriality and tolerance. Journal of Interprofessional Care 11, 9-21.

Easthaugh, A. 1996: Approaches to palliative care primary health care teams: a survey. Journal of Palliative Care 12(4), 47-50.

Field, D. 1998: Special not different: General practitioners' accounts of their care of dying people. Social Science and Medicine 46(9), 1111-9.

Fugeli, P. and Heath, I. 1996: The nature of general practice. British Medical Journal 312, 456-7.

Grande, G.E. 1997: Difficulties of symptom control and general practitioners' knowledge of patients' symptoms. Palliative Medicine 11, 399-406.

Ingleton, C., Field, D. and Clark, D. 1998: Qualitative evaluation and its relevance to palliative care. Palliative Medicine 12(3), 197-203.

Kendrick, T. and Hilton, S. 1997: Broader teamwork in primary care. British Medical Journal 314, 672-5.

Kumar, S. 2000: The new genetics and general practice: revolution or continuity? In Tovey, P. editor, Contemporary primary care. Buckingham: Open University Press, Chapter 6, 97-108.
Lipman, T. 2000: The future general practitioner: out of date and running out of time. British Journal of General Practice 50, 743-6.

Munday, D., Barnett, M. and Dale, J. 1999: Are GP out of hours co-operatives failing the dying. AUDGP Annual General Meeting (Poster), London.

National Council for Hospices and Specialist Palliative Care Services (London) 1995: Progress on national information project. Information Exchange.

Noble, B., Hughes, P., Ingleton, C. and Clark, D. 2001: Rural palliative care needs: a survey of primary care professionals in Powys, Wales. International Journal of Palliative Nursing 7(12), 610-15.

Oldham, J. and Rutter, I. 1999: Reforming British general practice (again). British Medical Journal 318, 747-9.

Pawson, R. and Tilley, N. 1997: Realistic evaluation. London: Sage Publications.

Powys Health Care NHS Trust. 1999: Review of community hospital and related services. Powys: Powys Health Care NHS Trust.

Robbins, M. 1998: Evaluating palliative care: Establishing the evidence base. Oxford: OUP.

RCG and CRMF. 1995: Royal College of General Practitioners and Cancer Relief Macmillan Fund. General Practice Palliative Care Facilitator Project. 1992-1994). London: Royal College of General Practitioners.

Seale, C. and Cartwright, A. 1994: The year before death. Aldershot: Avebury.

Seamark, D.A and Thorne, C.P. 1993: Knowledge and perception of a domiciliary hospice service among general practitioners and community nurses. British Journal of General Practice 43, 57-9.

Seamark, D., Moore, B., Tucker, H., Church, J. and Seamark, K. 2001: Community hospitals for the new millennium. British Journal of General Practice 51, 125-7.

Shipman, C., Thomas, M. and Addington-Hall, J.M. 2001a: Do GP facilitators make a difference in palliative care? Paper presented at the Palliative Care Research Forum, June 2001. London: Royal College of Physicians.

Shipman, C., Addington-Hall, J.M., Barclay, S., Briggs, J., Cox, I., Daniels, L. and Millar, D. 2001 b: Educational opportunities in palliative care: what do general practitioners want? Palliative Medicine 15, 191-6.

Sibbald, B., Addington-Hall, J.M. and Brenneman, D. 1994: Telephone versus postal surveys of GPs: Methodological considerations. British Journal of General Practice 44, 297-300.

Strauss, A. and Corbin, J. 1990: Basics of qualitative research: Grounded theory, procedures, and techniques. London: Sage.

Thomas, K. and Millar, D. 2001: Catalyst for change: Macmillan facilitators in cancer and palliative care. Palliative Care Today 2001, 54-6. 